\title{
Role of N-Acetylcystein in Protection against Cisplatin Nephrotoxicity
}

\author{
Sahar Refaat Habib ${ }^{a}$, Maggie Maher Ramzy ${ }^{b}$ and \\ Manal Ismail Abd Elghany ${ }^{c}$ \\ ${ }^{\mathbf{a}}$ Forensic Med. And Toxicology, ${ }^{\mathbf{b}}$ Biochemistry and ${ }^{\mathbf{c}}$ Pathology Departments \\ Faculty of Medicine, Minia University
}

\begin{abstract}
Background: Cisplatin (CDDP) is a cytotoxic therapeutic agent that causes many physiological adverse effects such as nephrotoxicity. Although $N$-acetylcystein (NAC) a thiol containing antioxidant, has been documented to be effective in attenuating $C D D P$ induced renal injury, the precise mechanisms involved in its renoprotection have not been completely clarified. Methods: Four groups of albino rats were used. The first group injected by saline as control, the second by $N A C$ (i.p.), the third by a single bolus of cisplatin (i.v.), and the last by NAC/CDDP, after 5 days from CDDP injection, investigations were conducted on the levels of serum urea and creatinine, oxidant/antioxidant status by estimation of malondialdehyde, catalase and reduced glutathione, and renal and systemic tumor necrosis factor-alpha (TNF- $\alpha)$. Also, renal tissues were examined histopathologically. Results: Administration of cisplatin to rats induced a significant increase in serum urea and creatinine levels in addition to severe alterations in renal tissue architecture. Cisplatin also increased malondialdehyde and decreased glutathione, and catalase in renal tissues. Also, $C D D P$ increased both renal and systemic TNF- $\alpha$. Administration of NAC markedly reduced the cisplatin-induced higher serum creatinine and urea levels and counteracted the effects of cisplatin on oxidative stress markers, protected the tissues from the cisplatin-induced lipid peroxidation, and increased TNF- $\alpha$ and improved renal tissue architecture. Conclusion: NAC protection is mediated by preventing the decline of antioxidant status, inhibit malondialdehyde and TNF- $\alpha$ and prevent necrosis and apoptosis from kidneys. These results have implications in use of NAC in human application for protecting against drug-induced nephrotoxicity.
\end{abstract}

Keywords: Cisplatin; Nephrotoxicity; Reduced glutathione; Malondialdehyde; Catalase; NAC; TNF- $\alpha$; apoptosis.

\section{INTRODUCTION}

Cisplatin,

Cisdiaminedichloroplatinum (CDDP), is an effective chemotherapeutic agent against multiple human cancers, including ovarian and head and neck malignancies ${ }^{[1]}$.
Although the therapeutic effects of cisplatin are improved by dose escalation, high-dose therapy is limited by its cumulative nephrotoxicity ${ }^{[2]}$. Reports of accidental overdose leading to renal failure indicate that cisplatin is 
sufficiently potent to be toxic to human ${ }^{[3]}$.

The mechanism of cisplatin-induced nephrotoxicity is not fully understood, but inflammation and oxidative stress have been reported in cisplatininduced nephrotoxicity [4, 5]. Hannemann and Baumann [6], reported that CDDP induced a high production of the lipid peroxidation product malondialdehyde (MDA), indirectly confirming a relationship between lipid peroxidation and platinum compound-induced nephrotoxicity. Ajith, et al. [5], reported that upon CDDP administration, reduced glutathione (GSH) content and catalase (CAT) activity are decreased.

Cytokines, particularly tumor necrosis factor- $\alpha$ (TNF- $\alpha$ ), appear to contribute to cisplatin-induced renal injury and to coordinate the activation of a large network of chemokines and cytokines in the kidney following cisplatin injection $^{\mathrm{v}]} \mathrm{l}$. So, inhibition of TNF- $\alpha$ production or its activity reduces cisplatin-induced renal dysfunction and structural damage ${ }^{[8]}$.

A number of anti-inflammatory and antioxidant agents, such as curcumin, vitamin $\mathrm{C}$, and vitamin $\mathrm{E}$, provide protective effects against cisplatininduced nephrotoxicity ${ }^{[5,9]}$. Although $\mathrm{N}$-Acetyl cysteine (NAC) a thiolcontaining antioxidant, has been documented to be effective in attenuating renal injury induced by CDDP, the precise mechanisms involved in its renoprotection have not been completely clarified ${ }^{[10]}$.

\section{Aim of the work}

The present study was conducted to evaluate the protective effect of NAC on cisplatin- induced nephrotoxicity by evaluating renal functions, oxidant/antioxidant status of the kidney tissues (in the form of catalase, MDA, reduced glutathione levels), renal and systemic TNF- $\alpha$ and renal histopathology in albino rats.

\section{MATERIALS \& METHODS}

\section{Animals}

A total of 40 male albino rats weighing $200 \pm 25 \mathrm{~g}$ were included in the current study and divided into four groups each of 10 rats. Each group was housed in separate metal cage and provided with standard rat chow and drinking water ad libitum.

\section{Drugs and design of work}

Group I was given intraperitoneal injection of saline once daily (vehicle of NAC) as a control, group II was treated by intraperitoneal injection of $250 \mathrm{mg} / \mathrm{kg}$ of NAC once daily, according to Luo et al. (2008) ${ }^{[10]}$, (NAC was obtained from Sedico Pharma Co. for Pharmaceuticals, in powder form and dissolved in saline). Group III received a single bolus injection of cisplatin, $5 \mathrm{mg} / \mathrm{kg}$ i.v. (MERCK génériques) via the tail vein under light ether anaesthesia to induce acute renal failure ${ }^{[10]}$. Group IV treated with intraperitoneal injection of NAC $(250 \mathrm{mg} / \mathrm{kg})$ once daily, at the second day, rats of that group were injected by a single bolus of cisplatin, $5 \mathrm{~m} / \mathrm{kg}$, i.v., i.e. saline and NAC were given daily for one week, while CDDP was given as one single bolus dose. After five days from cisplatin injections, rats were sacrificed by decapitation and blood samples were collected into clean tubes and allowed to stand at room temperature then centrifuged at $5000 \mathrm{rpm}$ for 10 
minutes to get the clear serum, kidneys were also separated from all groups for biochemical and histopathological analysis.

The experimental protocol was approved by the Ethics Review Committee for Animal Experimentation of Faculty of Medicine, Minia University.

Biochemical assay:

Serum urea was determined by using a urea enzymatic kit (BioDiagnostic Co., Egypt) and creatinine was assayed by creatinine kinetic kit (Bio-Diagnostic Co., Egypt).

Determination of renal MDA, GSH and CAT (oxidant/antioxidant status):

The renal cortex was separated, and subsequently homogenized in phosphate buffer saline (PBS) containing $\quad 0.05 \%$ tween-20 and protease inhibitor cocktail. The homogenate was centrifuged at 5000 rpm for $10 \mathrm{~min}$ at $4^{\circ} \mathrm{C}$. The resulting supernatant was used for determination of MDA, GSH, catalase activity and level of TNF- $\alpha$.

Catalase activity was determined by measuring the decomposition of hydrogen peroxide according to the manufacturers' instructions of colorimetric assay kit (Biodiagnostic, Egypt). The values are expressed as $\mathrm{U} / \mathrm{g}$ tissue. Each unit is defined as the amount of the enzyme required to decompose $1 \mu \mathrm{M}$ of $\mathrm{H}_{2} \mathrm{O}_{2}$ per minute [11].

The concentration of MDA as a marker of lipid peroxidation (LPO) was determined according to the method described by Buege and Aust ${ }^{[12]}$, which is based on the reaction with thiobarbituric acid, and was expressed as nmol/ $\mathrm{g}$ tissue.

GSH level was measured in renal cortex homogenate using colorimetric assay kit (Biodiagnostic, Egypt) according to the manufacturer's instruction. The method is based on the reduction of 5, 5'-dithiobis (2nitrobenzoic acid) with reduced glutathione to produce a yellow colored compound. The values were expressed as $\mathrm{mmol} / \mathrm{g}$ tissue ${ }^{[13]}$.

Measurement of TNF- $\alpha$ level:

The level of TNF- $\alpha$ in serum and renal cortical homogenate was determined by using enzyme-linked immunosorbent assay (ELISA) kit. (KOMA BIOTECH INC. KOREA) according to the manufacturer's instructions. A standard curve was constructed from standards provided by the manufacturer.

Histopathological examination:

One kidney of each rat was fixed in $10 \%$ formalin solution and then dehydrated in ascending grades of alcohol and embedded in paraffin. Sections at $4 \mu \mathrm{m}$-thickness were taken, stained with hematoxylin-eosin and evaluated by light microscope. The pathologist was blinded to treatment and evaluated the kidney sections at random for the presence or absence of lesion.

\section{Statistical analysis}

All data are presented as mean \pm SD. Significant difference among data were determined using one-way ANOVA and independent Student's $t$ test with SPSS version 10. P $<0.05$ denoted the presence of statistically significant difference 


\section{RESULTS}

\section{Biochemical assay:}

Renal function of rats treated by saline and NAC were normal as evidenced by normal serum urea and creatinine (Table 1). On the other hand administration of CDDP to rats is found to induce a marked renal failure, characterized by significant increase in serum urea $(172.1 \pm 2.33$ $\mathrm{mg} / \mathrm{dl}$.) and CR levels (3.48 \pm 0.33 $\mathrm{mg} / \mathrm{dl}$.) as compared to normal saline (urea: $24 \pm 3.23$ and CR: $1.04 \pm 0.23$ $\mathrm{mg} / \mathrm{dl}$.) and NAC groups (urea: $24.7 \pm 2.31$ and $\mathrm{CR}: 1.22 \pm 0.19$ $\mathrm{mg} / \mathrm{dl}$.) (table 1). The concentration of serum urea and creatinine in group IV (NAC+ CDDP) were significantly reduced (urea: $61.0 \pm 0.23$ and $\mathrm{CR}$ : $1.61 \pm 0.19 \mathrm{mg} / \mathrm{dl}$.) compared to the CDDP group.

Table 1: Effect of NAC, CDDP and CDDP plus NAC on serum urea and creatinine levels in rats (values are expressed as mean $\pm \mathrm{SD}$ )

\begin{tabular}{lll}
\hline Treatment & Serum urea mg/dl & Serum creatinine mg/dl \\
\hline Group I (Saline) & $24 \pm 3.23$ & $1.04 \pm 0.23$ \\
\hline Group II (NAC) & $24.7 \pm 2.31$ & $1.22 \pm 0.19$ \\
\hline Group III (CDDP) & $172.1 \pm 2.33^{*}$ & $3.48 \pm 0.33^{*}$ \\
\hline Group IV(NAC+CDDP) & $61.0 \pm 0.23^{* *}$ & $1.61 \pm 0.19 * *$ \\
\hline$* p<0.05$ versus group I and group II & \\
$* * p<0.05$ versus group III &
\end{tabular}

Table 2: Effect of NAC, CDDP and CDDP plus NAC on renal tissue MDA, GSH level and catalase activity (values are expressed as mean \pm SD)

\begin{tabular}{|c|c|c|c|}
\hline Treatment & $\begin{array}{l}\text { GSH } \\
\mathrm{mmol} / \mathrm{g} \text { tissue }\end{array}$ & $\begin{array}{l}\text { Catalase } \\
\text { U/g tissue }\end{array}$ & $\begin{array}{l}\text { MDA } \\
\text { nmol/g tissue }\end{array}$ \\
\hline group I (Saline) & $11.24 \pm 0.13$ & $5.65 \pm 0.11$ & $29.7 \pm 1.25$ \\
\hline Group II (NAC) & $11.33 \pm 0.12$ & $5.6 \pm 0.12$ & $29.5 \pm 1.35$ \\
\hline Group III (CDDP) & $7.96 \pm 0.30 *$ & $2.96 \pm 0.25 *$ & $46.3 \pm 1.49 *$ \\
\hline Group IV(NAC+CDDP) & $9.4 \pm 0.39 * *$ & $4.47 \pm 0.16^{* *}$ & $33.6 \pm 1.26^{* *}$ \\
\hline
\end{tabular}

Oxidant/antioxidant status of renal tissues: Catalase activity and level of GSH were significantly decreased after CDDP administration as compared with saline or NAC groups (table 2), while the concentration of MDA was found to be elevated in the CDDP-treated group (table 2). Administration of NAC was found to significantly improve the activity of catalase and the GSH level in renal tissues induced by CDDP (table 2). Administration of NAC also inhibited the CDDP-induced increase in the MDA level (table 2).

TNF- $\boldsymbol{\alpha}$ level: CDDP evoked a considerable increase in TNF- $\alpha$ abundance in the kidney and serum. Treating the rats with NAC significantly lessened the increment comparing with saline (control) and NAC groups (Fig.1-2). 


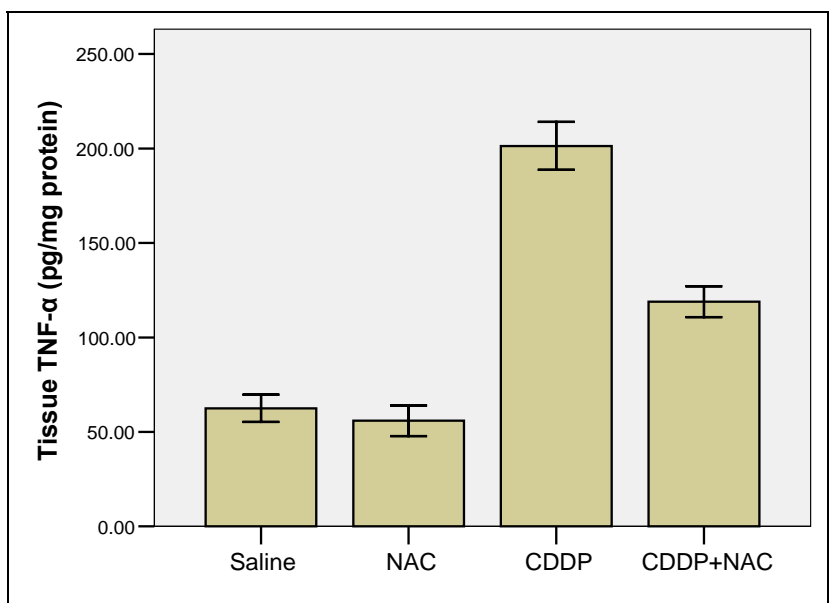

Fig.1 Effect of administration of NAC on CDDP-induced elevation in renal TNF- $\alpha$ level. Groups 1: Saline, 2: NAC, 3: CDDP and 4: NAC + CDDP.

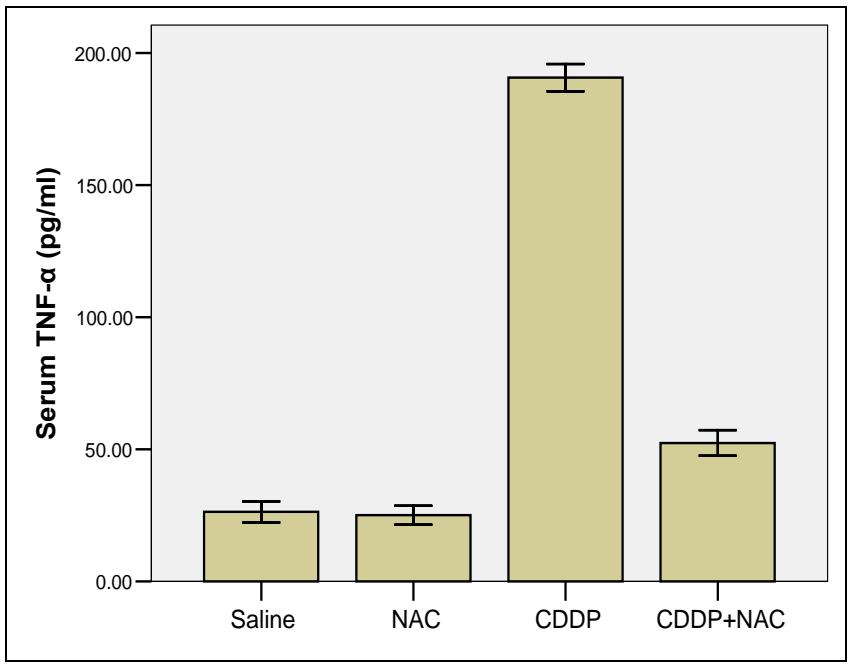

Fig. 2 Effect of administration of NAC on CDDP-induced elevation in serum TNF- $\alpha$ level. Groups 1: Saline, 2: NAC, 3: CDDP and 4: NAC + CDDP.

\section{Renal histopathological \\ examination:}

Histopathological analysis of kidneys of CDDP-treated rats showed various grades of tubular necrosis as well as apoptotic bodies (Fig 4 A \& B), compared with kidneys of group I and II (Fig.3), a finding that denotes irreversible kidney damage. The interstitium showed inflammatory cellular infiltrate (Fig $4 \mathrm{C}$ ) and the cells of the renal tubules exhibited hydropic degeneration and many of their lumenae contained hyaline casts 
and epithelial debris (Fig.4: A, B, C and D). Treatment with NAC dramatically improved the CDDP nephrotoxicity and this was evidenced as mild histopathological changes that could be detected in the form of interstitial nephritis and mild hydropic degeneration, the later represents reversible cell injury (Fig.5).

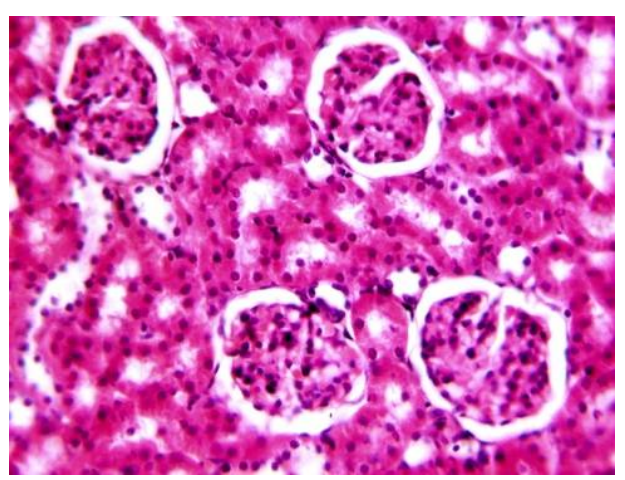

Fig. 3: Photomicrograph of normal kidney tissue of albino rat represents saline and NAC groups
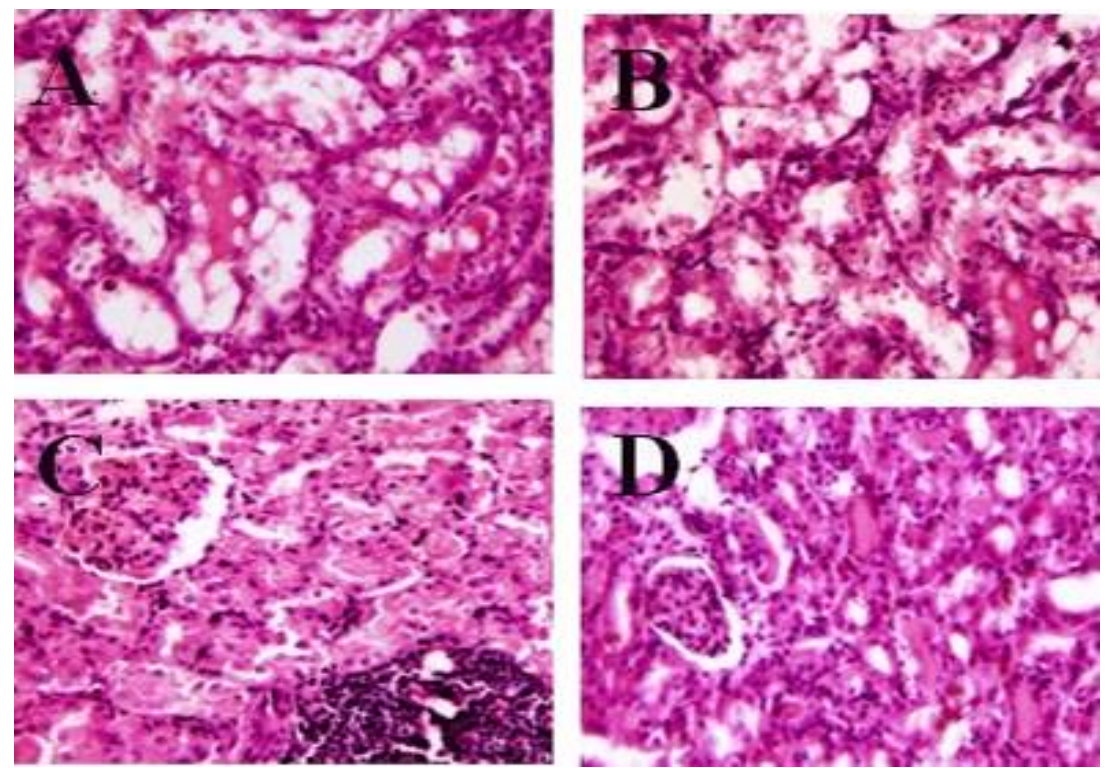

Fig. 4: A, B, C and D: Photomicrographs of albino rat kidneys represent CDDP group. A \& B: shows various grades of tubular necrosis as well as apoptotic bodies. C: the interstitium showed inflammatory cellular infiltrate. D: haemorrhage, hyaline casts, single cell necrosis and hydropic degeneration. 


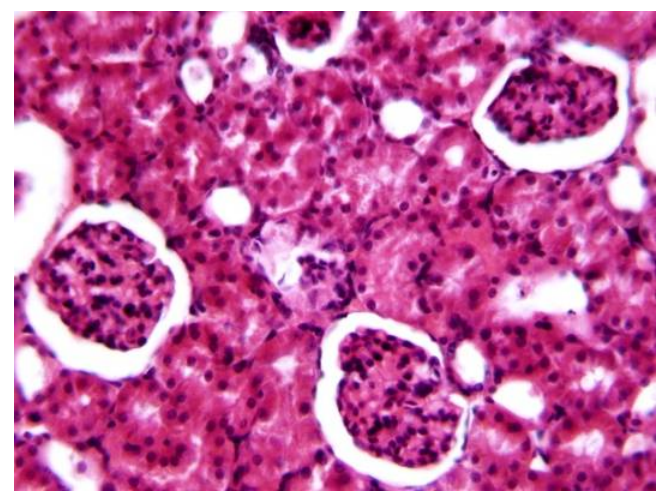

Fig.5: Photomicrograph of albino rat kidney of NAC/CDDP group, showing interstitial nephritis and hydropic degeneration.

\section{DISCUSSION}

Although the exact mechanisms underlying nephropathy secondary to CDDP have not been well established, it has been postulated that cisplatin therapy induces oxidative stress, principally involving reactive oxygen species (ROS) in renal tubular cells [14]. Oxidative stress is caused by various free-oxygen radicals including superoxide anion, hydrogen peroxide and hydroxyl radical [15]. The interaction of ROS with cellular components may result in damage to DNA, proteins, and lipids ${ }^{[16]}$.

A number of therapeutic agents have been evaluated experimentally and clinically against CDDP- induced nephrotoxicity, but none of them proved to be clinically effective as a complete protective agent. Nowadays, using various antioxidants for prophylaxis against toxic nephropathy is a current topic of research. Animal studies support a protective role of antioxidants against many nephrotoxic agent-induced renal dysfunction ${ }^{[17-20]}$. Furthermore, in humans, especially the use of NAC has been reported to show benefits against some drugs induced-nephropathy (radio contrast substances) ${ }^{[21]}$. NAC is a precursor of L-cystein and glutathione pathway and a scavenger of free radicals because it interacts with ROS ${ }^{[22]}$. The reactive thiol group on NAC may also directly bind to and inactivate platinum agents, as has been shown with other thiols ${ }^{[23]}$. Because of its favourable side-effect profile, low costs and positive results of randomized studies, NAC has gained favour in clinical practice as a preventive therapy.

In the present study, the role of NAC on renal functions, oxidant/antioxidant status, renal and systemic TNF- $\alpha$ and renal histopathology were investigated. A single bolus of intravenous administration of $5 \mathrm{mg} / \mathrm{kg}$ CDDP to rats induced significant increase in serum urea and creatinine compared to saline and NAC treated animals, suggesting an acute renal failure, which confirmed by disrupted architecture of kidney tissues which 
was in the form of tubular cell necrosis, apoptosis, foamy degeneration, hyaline casts, haemorrhage and interstitial inflammation. Dicky et al. ${ }^{[24]}$, also, demonstrated that CDDP treatment resulted in a consistently high serum urea and creatinine in three days and that these blood values correlated well with renal tubule damage seen histologically. Arany and Safirstein [25], reported that the kidney accumulates CDDP to a higher degree than any other organ, resulting in necrosis of the terminal portion of the proximal tubule and apoptosis in the distal nephron. CDDP induces apoptosis via activation of caspase $3^{[1,26,27]}$. Caspase- 3 can be activated by caspase 9 , which is activated by the release of cytochrome $c$ from the mitochondria ${ }^{[28,29]}$. NAC at $250 \mathrm{mg} / \mathrm{kg}$ administered before CDDP treatment significantly prevented the increase of serum urea and creatinine concentrations and markedly decreased CDDP-induced renal dysfunction and organ damage as confirmed by biochemical assays and histopathological examination. This may be explained by that most thiols are electrophilic and are thought to act as free radical scavengers. Scavenging of ROS by thiols protects tubular epithelium from caspase activation and from cell death ${ }^{[30]}$. The mechanism of protection of NAC may also be due to covalent binding of the molecule to the platinum, producing an inactive complex ${ }^{[31,32]}$. Schweitzer $^{[33]}$, showed that sulphurcontaining compounds may prevent CDDP from interacting with target molecule, displacing platinum after it is bound.
The balance between oxidants and antioxidants is crucial for the maintenance of the biological integrity of the tissues ${ }^{[34]}$.

The renal antioxidant status, such as CAT and reduced glutathione concentrations in this study, are significantly decreased in cisplatin alone-treated group of animals compared to saline and NAC groups. This is in agreement with the results of Zunino, et al. ${ }^{[35]}$ and Saad and Al-Rikabi ${ }^{[36]}$, who suggested that the levels of GSH in the kidney are significantly reduced by cisplatin treatment. The declined antioxidant status partially explains the mechanism of nephrotoxicity induced by cisplatin. The renal accumulation of platinum and covalent binding of renal protein may also play a role in nephrotoxicity ${ }^{[37]}$. Treatment of NAC $(250 \mathrm{mg} / \mathrm{kg})$ along with cisplatin could significantly prevent the depletion of that renal antioxidant system. Similar results were obtained by Luo et al., $2008^{[10]}$, who reported that NAC not only abolished but also significantly reversed the GSH decrease induced by CDDP. The decreased concentration of GSH increases the sensitivity of organs to oxidative and chemical injury $^{[38]}$. Studies with a number of xenobiotics often produced GSH depletion ${ }^{[39]}$. The depletion of GSH also seems to be a prime factor that permits lipid peroxidation in cisplatintreated group and subsequent toxicity [16]. Treatment with NAC rendered protection due to increase in GSH concentration could protect the renal cells from oxidant's attack. Appenroth et al., $1993^{[40]}$, reported that $\mathrm{N}$-acetylcystein, a sulfhydryl compound donor that acts by 
replenishing glutathione, was shown to "completely abolish the nephrotoxic effects of CDDP".

In the current study, CAT activity is significantly decreased in cisplatintreated rats, a similar result was also found by Maliakel, et al. ${ }^{[38]}$. A study done by Colbay, et al. ${ }^{[41]}$, on nephrotoxic effect of contrast media, suggested that the decrease in antioxidant enzyme activities (catalyse) in kidney tissues was due to over usage or consumption of that enzyme due to increased oxidative stress. The decreased activity of CAT in cisplatin-treated rats, in turn may increase the lipid peroxidation ${ }^{[16]}$. Thus, the level of MDA, as a result of lipid peroxidation, increased in CDDP-treated animals. This result also coincides with that of Malaiakel, et al. ${ }^{[38]}$. Hannemann and Baumann [6], reported that a high production of lipid peroxidation product MDA, indirectly confirming the relationship between lipid peroxidation and platinum compound-induced nephrotoxicity.

Pretreatment with NAC prevented lipid peroxidation (decreased MDA) by enhancing the renal CAT activity. Luo et al., ${ }^{[10]}$ and Kim et al. ${ }^{[42]}$, reported that reduced MDA level was responsible for prevention of CDDP nephrotoxicity. There is paucity of literatures concerning protective effect of NAC against CDDP effect on CAT and MDA. However, Colbay et al. [41], reported that NAC succeeded to lower MDA level and enhance CAT activity in an experiment studying protective effect of NAC against contrast media nephropathy. Hannemann and Baumann ${ }^{[6]}$, reported that other antioxidants such as alpha tocopherol or $(+)$ - cyanidanol prevented CDDP induced lipid peroxidation.

A crucial role for TNF- $\alpha$ in toxic and ischemic acute renal failure has been widely recognised ${ }^{[7,8,43,44]}$. In the present study, serum and renal tissue TNF- $\alpha$ level increased significantly after CDDP treatment. Lee et al. ${ }^{[45]}$, reported that CDDP stimulates systemic TNF- $\alpha$ and Ramesh et al. [46], reported that CDDP stimulates TNF- $\alpha$ secreted by kidney epithelial cells. Ramesh and Reeves ${ }^{[7]}$, have shown that cisplatin nephrotoxicity is characterized by the activation of pro-inflammatory cytokines and chemokines, and that TNF- $\alpha$ plays a central role in the activation of these cytokines. Pretreatment with NAC in the current study reduced overproduction of systemic and renal TNF- $\alpha$. There is a paucity of literatures concerning the effect of NAC on both systemic and renal TNF- $\alpha$, but Luo et al. ${ }^{[10]}$, reported that NAC inhibited TNF- $\alpha$ mRNA. Inhibition of TNF- $\alpha$ is capable of attenuating CDDP-induced renal injury ${ }^{[7]}$, this also explains renoprotective effect of NAC.

Conclusion and recommendations:

It could be concluded that the antioxidant NAC preserve GSH level, arrange cellular immunity, prevent lipid peroxidation, keep catalase activity, inhibit both renal and systemic TNF- $\alpha$ and protect renal tissues from CDDP toxicity, hence show protective effects against nephrotoxic agents. So, it might be used for protection from CDDP nephrotoxicity after modification of its dose to fit human use as the dose used in the present study was big. 


\section{REFERENCES}

1. Wu YJ, Muldoon LL, and Neuwelt EA (2005). The chemoprotective agent Nacetylcystein blocks cisplatininduced apoptosis through caspase signaling pathway. $J$. Pharmacol. Exp. Ther., 312:424431.

2. Meyer KB, Medias NE (1994). Cisplatin nephrotoxicity. Miner Electrolyte Metab., 20: 201-213.

3. Chu G, Mantin R, Shen Y, Baskett $G$ and Sussman $H$ (1993). Massive cisplatin overdose by accidental substitution for carboplastin. Toxicity and management. Cancer 72: 3707-3714.

4. Badary OA, Abdel-Maksoud S, Ahmed WA and Owieda GH (2005). Naringenin attenuates cisplatin nephrotoxicity in rats. Life Sci., 76: 2125-2135.

5. Ajith TA, Usha $S$ and Nivitha $V$ (2007). Ascorbic acid and alpha tocopherol protect anticancer drug cisplatin induced nephrotoxicity in mice: a comparative study. Clin. Chim. Acta 375: 82-86.

6. Hannemann $\mathbf{J}$ and Baumann $K$ (1990). Nephrotoxicity of cisplatin, carboplatin and transplatin. A comparative in vitro study. Arch. Toxicol., 64:393-400.

7. Ramesh $G$ and Reeves WB (2002). TNF- $\alpha$ mediates chemokine and cytokine expression and renal injury in cisplatin nephrotoxicity. J. Clin. Invest., 110: 835-842.
8. Ramesh $G$ and Reeves WB (2004). Salicylates reduces cisplatin nephrotoxicity by inhibition of tumor necrosis factor- $\alpha$.. Kidney Int., 65: 490498.

9. Kuhad A, Pilkhwal S, Sharma S and Tirkey $N$ (2007). Effect of curcumin on inflammation and oxidative stress in cisplatininduced experimental nephrotoxicity. J. agric. Chem., 55: 10150-10155.

10. Luo J, Tsuji T, Yasuda H, Sun $Y$, Fujigaki $Y$ and Hishida $A$ (2008). The molecular mechanisms of the attenuation of cisplatin- induced acute renal failure by $\mathrm{N}$-acetylcystein in rats. Nephrol. Dial. Transplant., 23: 2198-2205.

11. Aebi H (1984). Catalase in vitro. Methods Enzymol., 105: 121-126.

12. Buege AJ and Aust SD (1978). Microsomal lipid peroxidation. Methods Enzymol., 52: 302-310.

13. Butler E, Duron $O$ and Kelly BM (1963). Improved method for the determination of blood GSH. J. Lab. \& Clin. Med., 61: 882890.

14. Jordan $P$ and Carmo-Fonseca M (2000). Molecular mechanisms involved in cisplatin cytotoxicity. Cell Mol. Life Sci., 57: 1229-35.

15. Baek SM, Kwon CH, Kim JH, Woo JS and Kim YK (2003). Differential roles of hydrogen peroxide and hydroxyl radical in cisplatin-induced cell death in renal proximal tubular epithelial cells. J. Lab. Clin. Med., 142: 178- 86.

16. An $Y$, Xin $H$, Yan $W$ and Zhou $X$ (2010). Amelioration of 
cisplatin-induced nephrotoxicity by pravastatin in mice. Experimental and Toxicologic Pathology. doi: 10.1016/ j.etp.2009.12.002.

17. Gazi S, Altun $A$ and Erdogan $O$ (2006). Contrast-induced nephropathy: preventive and protective effects of melatonin. $J$. Pineal Res., 41: 53-7.

18. Mazzon E, Britti D, De Sarro A, Caputi AP and Cuzzocera $S$ (2001). Effect of $\mathrm{N}$-acetyl cystein on gentamycin-mediated nephropathy in rats. Eur. $J$. Pharmacol., 424: 75-83.

19. Tariq M, Morais C, Sobk S, Al Solaiman $M$ and Al Khader $A$ (1999): N-acetylcystein attenuates cyclosporine-induced nephrotoxicity in rats. Nephrol. Dial. Transplant., 14: 923-9.

20. Shaikh ZA, Zaman, K, Tang W and Vu T (1997). Treatment of chronic cadmium toxicity by $\mathrm{N}-$ acetylcystein. Toxicol. Lett., 104: 137-42.

21. Tepel M, Van der Giet M, Schwarzfeld C, Laufer U, Liermann D and Ziedek W (2000). Prevention of radiographic-contrast-agentinduced reduction in renal function by acetylcystein. $N$. Engl. J. Med., 343: 180-4.

22. Zafarullah M, Li WQ, Sylvester $J$ and Ahmad $M$ (2003). Molecular mechanisms of Nacetylcystein actions. Cell Mol. Life Sci., 60:6-20.

23. Muldoon LL, WalkerRosenfeld SL, Hale C, Purcell SE, Bennett LC and Neuwelt EA (2001). Rescue from enhanced alkylator-induced cell death with low molecular weight sulfur-containing

chemoprotectants. J. Pharmacol. Exp. Ther., 296:797-805.

24. Dickey DT, Wu YJ, Muldoon $L L$ and Neuwelt EA (2005). Protection against cisplatininduced toxicities by $\mathrm{N}$ acetylcystein and sodium thiosulfate as assessed at the molecular, cellular, and in vivo levels. JPET., 314(3):1052-1058.

25. Arany $I$ and Safirstein RL (2003). Cisplatin nephrotoxicity. Semin Nephrol., 23: 460-464.

26. Siddik ZH (2003). Cisplatin: mode of cytotoxic action and molecular basis of resistance. Oncogene 22:7265-7279.

27. Ludwig $\mathbf{T}$ and Oberleithner $\mathbf{H}$ (2004). Platinum toxicity in cultured renal cells. Cell Physiol Biochem. 14:431-440.

28. Zhan $Y$, Van de Water B, Wang Y and Stevens JL (1999). The roles of caspase-3 and bcl-2 in chemically-induced apoptosis but not necrosis of renal epithelial cells. Oncogene 18:6502-6512.

29. Schuler M, Bossy-Wetzel E, Goldstein JC, Fitzgerald $P$ and Green GR (2000). P53 induces apoptosis by caspase activation through mitochondrial cytochrome c release. J. Biol. Chem., 275:7337-7342.

30. Basnakian AG, Kaushal GP and Shah SV (2002). Apoptotic pathways of oxidative damage to renal tubular epithelial cells. Antioxid. Redox. Signa, 4:915924.

31. Neuwelt EA, Pagel MA, Hasler BP, Deloughery TG and Muldoon L L (2001). 
Therapeutic efficacy of aortic administration of $N$-acetylcystein as a chemoprotectant against bone marrow toxicity after intracarotid administration of alkylators, with or without glutathione depletion in a rat model. Cancer Res., 61:78687874.

32. Fuertes MA and Castilla $J$ (2003). Cisplatin biochemical mechanism of action: from cytotoxicity to induction of cell death through interconnections between apoptotic and necrotic pathways. Curr. Med. Chem., 10:257-266.

33. Schweitzer VG (1993). Ototoxicity of chemotherapeutic agents. Otolaryngol. Clin. North. Am., 26:759-785.

34. Sadzuka Y, Shoji T and Takino $Y$ (1992). Effect of cisplatin on the activities of enzymes which protect against lipid peroxidation. Biochem. Pharmacol., 43: 18735.

35. Zunino F, Tofanetti O, Besati A, Cavalletti $E$ and Savi $G$ (1983). Protective effect of reduced glutathione against cisdichlorodiammine platinum(II)induced nephrotoxicity and lethal toxicity. Tumori. 69: 105-11.

36. Saad SY and Al-Rikabi AC (2002). Protection effects of taurine supplementation against cisplatin-induced nephrotoxicity in rats. Chemotherapy 48: 42-8.

37. Litterst CL and Schweitzer VG (1988). Covalent binding of platinum to renal protection from sensitive and resistant guinea pigs treated with cisplatin: possible role in nephrotoxicity. Res.
Commun. Chem. Pathol.

Pharmacol., 61: 35-48.

38. Malaiakel DM, Kagiya TV and Nair CK (2008). Prevention of cisplatin-induced nephrotoxicity by glucosides of ascorbic acid and $\alpha$-tocopherol. Experimental and Toxicologic Pathology 60: 521-527.

39. Michel J R, Mcmartry RJ, Statham CN and Nelson SD (1977). Molecular basis for several drug induced nephropathies. Am. J. Med., 62: 518-26.

40. Appenroth D, Winnefeld K, Schroter H and Rost M (1993). Beneficial effect of acetylcystein on cisplatin nephrotoxicity in rats. J. Appl. Toxicol., 13:189-192.

41. Colbay M, Yuksel S, Uslan I, Acarturk G, Karaman O, Bas O, Mollaoglu H, Yagmurca $M$ and Ozen OA (2010). Novel approach for the prevention of contrast nephropathy. Experimental and Toxicologic Pathology 62: 81-89.

42. Kim SH, Hong KO, Hwang JK et al., (2005). Xanthorrhizol has a potential to attenuate the high dose cisplatin-induced nephrotoxicity in mice. Food Chemical Toxicol., 43: 117-122.

43. Ramesh $G$ and Reeves WB (2005). P38 MAP Kinase inhibition ameliotates cisplatin nephrotoxicity in mice. Am. J. Physiol. Renal Physiol., 289: F166-F174.

44. Daemen M A, Vande Ven MW, Heinman et al., (1999). Involvement of endogenous interleukin-10 and tumor necrosis factor-alpha in renal ischemia- 
reperfusion injury.

Transplantation 67: 792-800.

45. Lee S, Kim W, Moon SO, Sung MJ, Kim DH, Kang, KP, Jang YB, Jang KY and Park SK (2006). Rosiglitazone ameliorates cisplatin-induced renal injury in mice. Nephrol. Dial. Transplant. 21:2096-2105.
46. Ramesh G, Kimball SR, Jefferson LS and Reeves WB (2007). Endotoxin and cisplatin synergistically stimulate TNF- $\alpha$ production by renal epithelial cells. Am. J. Physiol. Renal Physiol., 292: F812-F819. 


\section{دور ال ن-أستيل سيستايين في الحماية من تسمم الكلى بالسيسبلاتين}

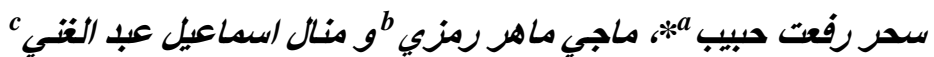

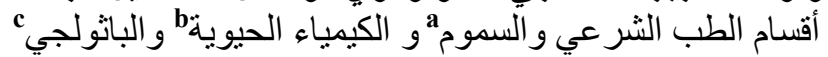

$$
\begin{aligned}
& \text { كلية الطب- جامعة المنيا }
\end{aligned}
$$

يعتبر عقار السيسبلاتين من أثهر العقاقير التي تستخدم في علاج السرطان. ومع هذا فهو يسبب الكثير من

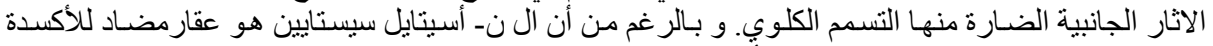

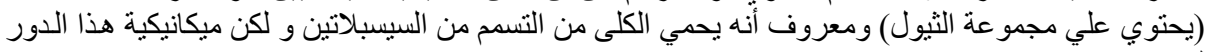
في هذا البحث تم حقن فئر ان التجارب البيضاء بالمحلول الملحي كمجموعة ضيابطة، و المجمو عة الثانية بعقار

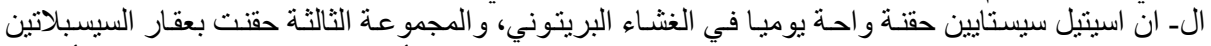

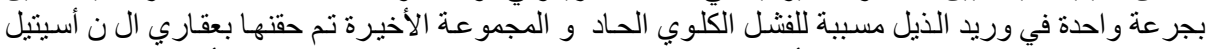

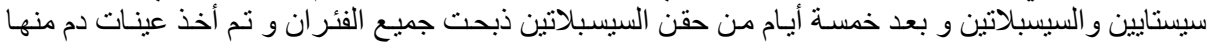

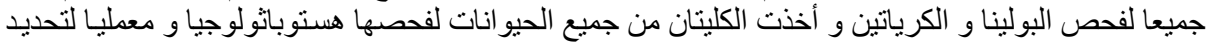

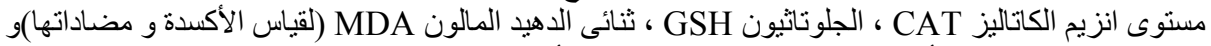

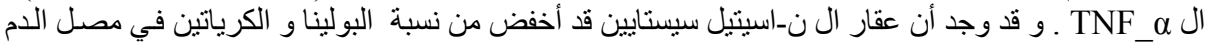

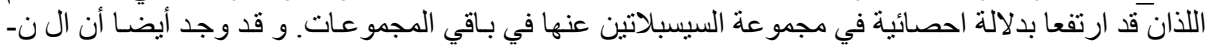

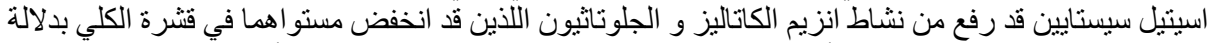

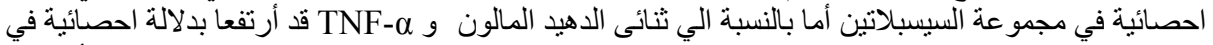

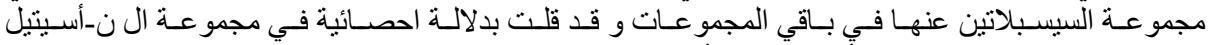

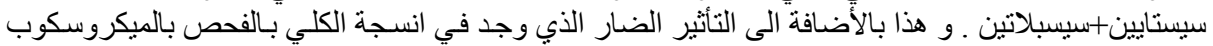

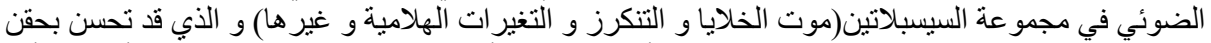

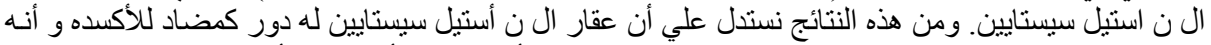

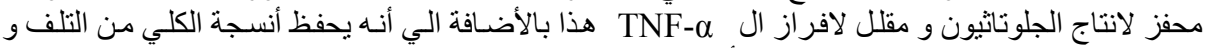

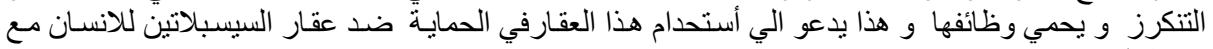
ضبط الجرعة . ن و 